\title{
Predictive factors of subjective sleep quality and insomnia complaint in patients with stroke: implications for clinical practice
}

\author{
PATRÍCIA C. DA ROCHA, MARINA T.M. BARROSO, ANA AMÁLIA T.S.G. DANTAS, \\ LUCIANA P. MELO and TANIA F. CAMPOS
}

Universidade Federal do Rio Grande do Norte, Departamento de Fisioterapia, Avenida Senador Salgado Filho, 3000, 59066-800 Natal, RN, Brasil

Manuscript received on June 17, 2011; accepted for publication on January 10, 2013

\begin{abstract}
The complaints regarding sleep problems have not been well identified after a stroke. The aim of this study was to investigate the predictive factors of sleep quality and insomnia complaints in patients with stroke. A total of 70 subjects, 40 patients ( $57 \pm 7$ years) and 30 healthy controls (52 \pm 6 years) assessed by the Pittsburgh Sleep Quality Index (PSQI) and the Sleep Habits Questionnaire took part in the study. The data were analyzed using the chi-square test, the Student's t-test and logistic regression analysis. On average, the patients showed poor sleep quality (patients: $6.3 \pm 3.5$; controls: $3.9 \pm 2.2 ; \mathrm{p}=0.002$ ) and insomnia complaint was the most prevalent (patients: $37.5 \%$; controls: $6.7 \% ; \mathrm{p}=0.007$ ). The absence of insomnia complaint $(\mathrm{OR}=0.120 ; 95 \% \mathrm{CI}=0.017-0.873 ; \mathrm{p}=0.036)$ and the decreased latency of sleep $(\mathrm{OR}=$ $0.120 ; 95 \% \mathrm{CI}=0.017-0.873 ; \mathrm{p}=0.036)$ were the protective factors of sleep quality. Female sex $(\mathrm{OR}=$ $11.098 ; 95 \% \mathrm{CI}=1.167-105.559 ; \mathrm{p}=0.036)$ and fragmented sleep $(\mathrm{OR}=32.040 ; 95 \% \mathrm{CI}=3.236-317.261$; $\mathrm{p}=0.003$ ) were the risk factors for insomnia complaint. We suggest that complaints of poor sleep quality and insomnia should be given priority assessment during clinical diagnosis of sleep disorders in stroke.
\end{abstract}

Key words: insomnia, sleep disturbances, sleep quality, stroke.

\section{INTRODUCTION}

Stroke, defined as a focal disturbance of cerebral function as a result of vascular alterations, is a pathology that represents a serious public health problem in Brazil, given that the country has the highest death rate by stroke in Latin America and that it is still neglected by the population and even by health professionals (Lotufo 2005, Pontes-Neto et al. 2008, Coca et al. 2008).

In addition to physical and cognitive impairment, the occurrence of sleep disorders is an

Correspondence to: Tania Fernandes Campos

E-mail: taniacampos@ufrnet.br important aspect that needs to be considered in the clinical approach to patients with stroke. The rehabilitation process, for example, which occurs from the initial stage following the stroke, is continuous and prolonged in many cases, and may be compromised if patients experience poor sleep quality or sleep disturbances, mainly because sleep is a function that interferes significantly in the learning and memory consolidation processes (Curcio et al. 2006, Wright Jr et al. 2006).

The diagnosis and treatment of sleep disorders is a field that has been expanding considerably in recent years, with studies on the physiology and 
physiopathology of sleep. The alterations in the amount, quality or regulation of sleep include: insomnia, hypersomnia, obstructive sleep apnea syndrome, restless legs syndrome, circadian rhythm disorders, which encompass, among others, jet lag, delayed and advanced sleep phase syndrome. On the other hand, the alterations in behavioral or physiological events that occur during sleep in general in specific stages of this sleep or in sleepwake transitions include: sleep walking, night terrors, nightmares, sleep-talking, teeth grinding, nocturnal enuresis and snoring, among others (AASM 2001).

Studies on patients with stroke show the occurrence of disturbed sleep, the main disorder being obstructive sleep apnea syndrome, which occurs in $60 \%$ to $90 \%$ of patients (Koch et al. 2007, Srijithesh et al. 2011). Complaints of insomnia and excessive daytime somnolence are also found in this clinical population (Ferrea et al. 2010). Campos et al. (2005) showed various episodes of dozing at different times and poor sleep quality in chronic stage stroke patients.

Literature studies related to sleep in stroke patients have little mention of sleep problem complaints and their relationship with sleep quality. We believe that the identification of sleep disturbances in patients with stroke, by means of reports and complaints, is crucial in the diagnostic and therapeutic clinical approach. Self-reporting methods, such as sleep questionnaires, measure the sleep quality experienced by the patient. To consider both the quantitative and qualitative aspects of sleep is important to identify the possible complaints of sleep disorders earlier. Moreover, these subjective methods are easily managed, inexpensive and of wide applicability, in both clinical practice and research (Chartier-Kastler and Davidson 2007, Gallasch and Gradisar 2007). The identification of impaired sleep quality and frequency of sleep disturbance complaints in patients with stroke may lead to corrective measures, such as the establishment of proper routines and habits, as well as more appropriate times for therapeutic interventions. Thus, the aim of this study was to investigate the predictive factors of subjective sleep quality and of insomnia complaints in patients with stroke.

\section{MATERIALS AND METHODS}

SAMPLE

The sample was composed of 70 subjects, including a group of 40 patients with diagnosis of unilateral stroke enrolled at physical therapy services in the city of Natal, Brazil, who were compared to a group of 30 healthy employees of the Universidade Federal do Rio Grande do Norte. The group of patients was composed of 27 men and 13 women, aged between 45 and 65 years ( $57 \pm 7$ years), lesion time between 1 and 36 months (11 \pm 9 months), with 24 and 16 patients presenting impaired right and left cerebral hemisphere, respectively. The group of healthy individuals was composed of 15 men and 15 women, aged between 45 and 64 years ( $52 \pm 6$ years). The schooling level of the participants varied between primary and secondary education. The exclusion criteria adopted for the patients were: recurrent cerebral lesion, serious cognitive disorders, aphasia and the use of tranquilizers, antidepressants or neuroleptics. Control, individuals with cognitive disorders, shift workers or those who had taken a recent transmeridian trip were excluded.

\section{PROCEDURES}

The study was approved by the institutional Research Ethics Committee. The participants were informed of the study procedures and asked to sign a consent form. The patients were interviewed and provided the following information: identification, results of computerized tomography, history of the disease, risk factors present, medication used and lesion time. The Cumulative Illness Rating Scale (CIRS), an assessment scale of comorbidities, was used with the healthy individuals. This scale consists of a standardized clinical evaluation 
that investigates the overall health data of the individual in six organic systems, with scores ranging from 0 to 4 , to ensure the current healthy status of the individual (Parmelee et al. 1995). To determine the degree of neurological impairment of the patients, we used the National Institute of Health Stroke Scale (NIHSS) protocol validated in Brazil by Caneda et al. (2006). The scale is composed of 11 items that assess awareness level, eye movements, visual field, facial movements, motor function and upper and lower limb ataxia, as well as sensitivity, language, presence of disarthria and visual-spatial neglect. The total score, ranging from 0 to 42 points, is the sum of the points of each item, in which higher scores indicate greater neurological impairment.

The Horne-Östberg Questionnaire (Horne and Östberg 1976) was then applied to identify the chronotype of the subjects. This questionnaire is composed of 19 questions about preferable times for going to sleep and waking up. Finally, a subjective assessment of sleep was conducted using the Pittsburgh Sleep Quality Index (PSQL) (Buysse et al. 1989), validated in Brazil by Ceolim (1999) and the Sleep Habits Questionnaire (Vinha et al. 2002). The PSQL is a questionnaire used to assess the sleep quality of an individual through 7 components: subjective sleep quality, latency, duration, efficiency, sleep disorders, use of sleep medication and daytime dysfunction. The scores of all the components are added to obtain a value between 0 and 21 , in which scores higher than 5, indicate poor sleep quality. The Sleep Habits Questionnaire is a validated and standardized instrument with 47 questions that aims to draw a sleep-wake profile of the subject assessed. In this study information from this instrument about sleep was used to determine complaints of: insomnia (question 16), difficulty falling asleep ("yes" answer on question 18), fragmented sleep ("yes" answer on question 22), sleep apnea ("yes" answer on question 26), restless legs syndrome ("moving the legs" answer on question 28), nightmares ("yes" answer on question 24), teeth grinding ( "grinding teeth" answer on question 28), sleep talking ("talk in sleep" answer question 28), snoring ("snoring " answer on question 28), sleep walking ("sleep walk" answer on question 28), rhythmic movement disorder ("hit head" answer on question 28) and night terrors ("scream while sleeping" answer on question 28).

\section{DATA ANALYSIS}

Data analysis was conducted using SPSS 15.0 (Statistical Package for the Social Science Software) and a significance level less than $5 \%$ for all the statistical tests. The chi-square test, with Yates' correction (when necessary) was used to compare the patients and controls in terms of the absolute and percentage frequency of the variables: sex, age, schooling and chronotype, as well as the frequency of sleep disorder complaints. After normal distribution was confirmed (Kolmogorov-Smirnov test) in the PSQI scores and their components, nonpaired Student's t-test was applied to compare the patients to the healthy individuals. In the group of patients the chi-square test was used to determine the association between sleep quality and the clinical variables, and between insomnia complaint and the demographic and clinical variables, PSQI categories, and other complaints of sleep disorder. Logistic regression analysis was carried out using the stepwise backward method, to identify the predictive factors of subjective sleep quality (with the categorized PSQI score) and of insomnia complaint in the patients.

\section{RESULTS}

The chi-square test showed no significant difference between the groups in terms of the absolute and percentage frequency for sex, age, schooling, and chronotype (Table I). However, the non-paired Student's t-test did show a significant difference with respect to the mean PSQI score, with a higher mean score for the patients $(6.3 \pm 3.5)$ compared to the controls $(3.9 \pm 2.2)(p=0.002)$. 
TABLE I

Comparison of absolute and percentage frequency of the variables sex, age, schooling and chronotype, between patients and healthy controls, using the Chi-square test.

\begin{tabular}{|c|c|c|c|c|c|c|}
\hline \multirow{2}{*}{\multicolumn{2}{|c|}{ VARIABLES }} & \multicolumn{2}{|c|}{ PATIENTS } & \multicolumn{2}{|c|}{ CONTROLS } & \multirow{2}{*}{$p$ value } \\
\hline & & $\mathbf{N}$ & $\%$ & $\mathbf{n}$ & $\%$ & \\
\hline \multirow{2}{*}{ Sex } & Female & 13 & 32.5 & 15 & 50.0 & 0.139 \\
\hline & & 27 & 67.5 & 15 & 50.0 & \\
\hline \multirow{2}{*}{ Age } & $\geq 60$ years & 15 & 37.5 & 5 & 16.7 & 0.060 \\
\hline & & 25 & 62.5 & 25 & 83.3 & \\
\hline \multirow{2}{*}{ Schooling } & Primary & 32 & 80.0 & 18 & 60.0 & 0.067 \\
\hline & & 8 & 20.0 & 12 & 40.0 & \\
\hline \multirow{3}{*}{ Chronotype } & Indifferent & 4 & 10.0 & 4 & 13.4 & 0.910 \\
\hline & Moderate Morning & 18 & 45.0 & 13 & 43.3 & \\
\hline & Extreme Morning & 18 & 45.0 & 13 & 43.3 & \\
\hline
\end{tabular}

In regard to the PSQI scores, a significant difference was found between patients and controls in terms of latency $(p=0.019)$, duration $(p=0.039)$ and daytime dysfunction $(\mathrm{p}=0.001)$. The main complaints reported by the participants were: insomnia, fragmented sleep, sleep apnea, restless legs syndrome, nightmares, teeth grinding, sleep talking, snoring, sleep walking and night terrors, but a significant difference was found only in the frequency of insomnia complaint in the patients and controls, with the patients showing greater frequency (Figure 1). The association between sleep quality and clinical variables was investigated and the result obtained showed no significant difference between the patients with good and poor quality regarding lesion time $(p=0.746)$, cerebral hemisphere affected $(p=0.601)$ and neurological degree $(p=0.749)$.

Logistic regression analysis to identify the predictive factors of sleep quality in the patients was conducted with the variables that were significant in the previously mentioned Student's t-test and chisquare test. Two models were built and the second model better identified the variables related to sleep quality. Significant values were found for insomnia (among the sleep disorder complaints) and latency (among the PSQI components). The upper and lower limits of the confidence interval for the Odds Ratio showed that absence of insomnia complaint and decreased latency were the main protective factors of sleep quality (Table II).

To select the variables associated with insomnia complaint in the patients, an analysis was conducted using the chi-square test with the following variables: sex, age, schooling, lesion time, cerebral hemisphere affected and neurological degree. The analysis showed that the female patients and those with impaired right cerebral hemisphere had more insomnia complaints (Table III). A significant association was observed between insomnia complaint in the patients and the PSQI components subjective sleep quality $(86.7 \%$; $p=0.01)$ and sleep latency $(66.7 \% ; p=0.007)$, showing that the higher frequency of compromised subjective sleep quality and latency was in the group of patients complaining of insomnia.

Analysis of the association between insomnia complaint in the patients and the other sleep disorders showed a greater number of complaints regarding difficulty in falling asleep $(53.3 \%$; $\mathrm{p}=$ $0.029)$ and of fragmented sleep $(86.7 \% ; p=0.001)$ in the patients with insomnia complaints than in those with no such complaints. 


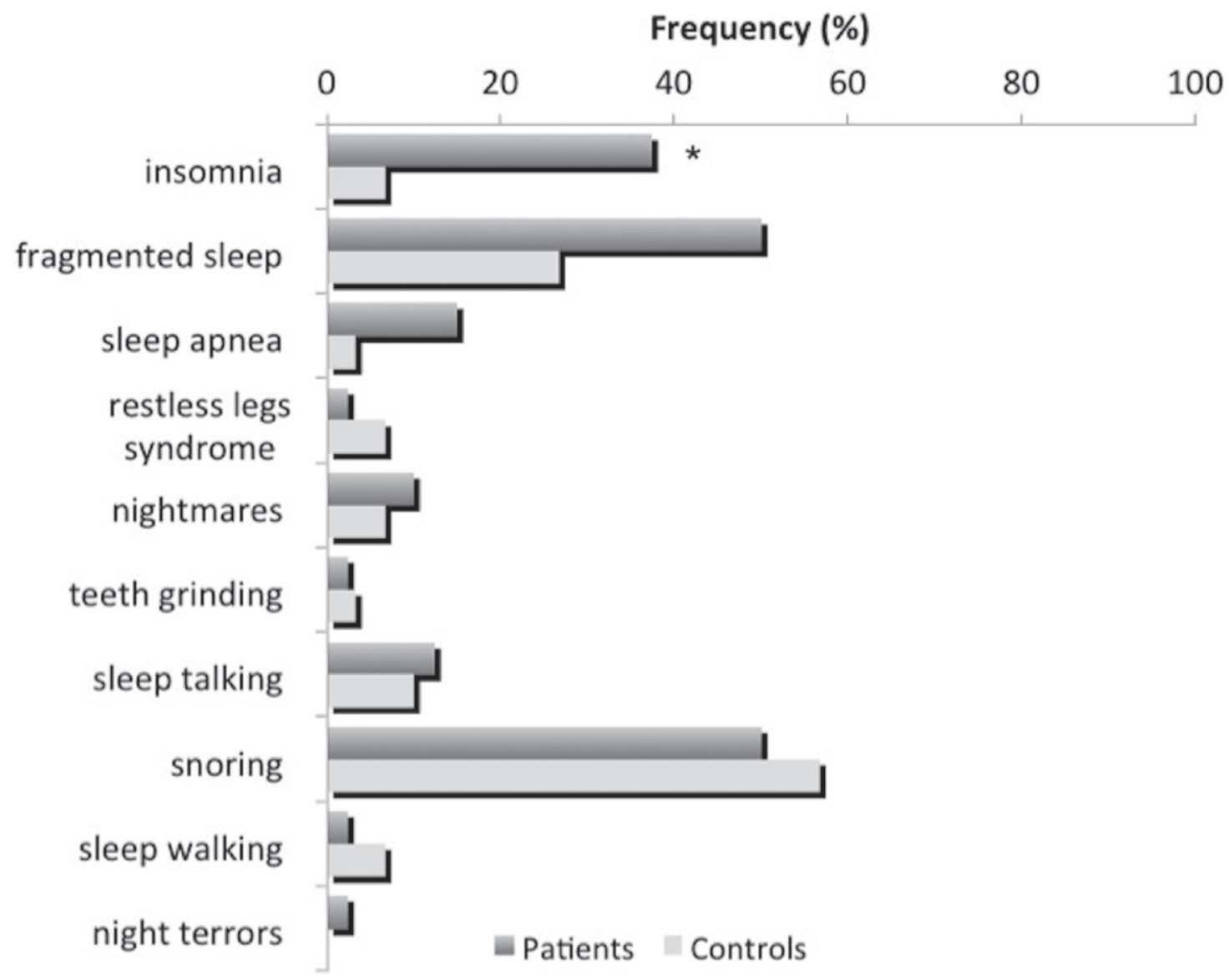

Figure 1 - Frequency percentage of complaints of sleep problems. * Significant difference between patients and controls. $\mathrm{p}=0.007$.

TABLE II

Logistic regression models (Odds Ratio, upper and lower limits of the $\mathbf{9 5 \%}$ confidence interval and p-value) considering insomnia complaint, subjective quality, latency, duration and daytime dysfunction as independent variables and sleep quality as the dependent variable.

\begin{tabular}{lcccc}
\hline VARIABLES & ODDS RATIO & LOWER & UPPER & $\boldsymbol{P}$ \\
\hline Model 1 & & & & \\
Insomnia & 0.118 & 0.016 & 0.895 & 0.036 \\
$\quad$ Subjective quality & 0.388 & 0.019 & 7.975 & 0.539 \\
Latency & 0.141 & 0.019 & 1.069 & 0.058 \\
$\quad$ Duration & - & - & - & 0.999 \\
Daytime dysfunction & 0.080 & 0.006 & 1.071 & 0.056 \\
Model 2 & & & & \\
Insomnia & 0.120 & 0.017 & 0.873 & $\mathbf{0 . 0 3 6}$ \\
$\quad$ Latency & 0.120 & 0.017 & 0.873 & $\mathbf{0 . 0 3 6}$ \\
$\quad$ Duration & - & - & - & 0.999 \\
Daytime dysfunction & 0.082 & 0.006 & 1.052 & 0.055 \\
\hline
\end{tabular}


TABLE III

Comparison of absolute and percentage frequency of the demographic and clinical variables, between patients with and without insomnia.

\begin{tabular}{|c|c|c|c|c|c|c|}
\hline \multirow{2}{*}{\multicolumn{2}{|c|}{ VARIABLES }} & \multicolumn{5}{|c|}{ PATIENTS } \\
\hline & & \multicolumn{2}{|c|}{ With insomnia } & \multicolumn{2}{|c|}{ Without insomnia } & \multirow[b]{2}{*}{$p$ value } \\
\hline & & n & $\%$ & $\mathbf{N}$ & $\%$ & \\
\hline \multirow[t]{2}{*}{ Sex } & Female & 20 & 80.0 & 7 & 46.7 & 0.030 \\
\hline & Male & 5 & 20.0 & 8 & 53.3 & \\
\hline \multirow[t]{2}{*}{ Age } & $\geq 60$ years & 7 & 28.0 & 8 & 53.3 & 0.109 \\
\hline & $<60$ years & 18 & 72.0 & 7 & 46.7 & \\
\hline \multirow[t]{2}{*}{ Schooling } & Primary & 18 & 28.0 & 14 & 93.3 & 0.221 \\
\hline & Secondary & 7 & 72.0 & 1 & 6.7 & \\
\hline \multirow[t]{2}{*}{ Lesion time } & $\leq 12$ months & 17 & 68.0 & 10 & 66.7 & 0.930 \\
\hline & $>12$ months & 8 & 32.0 & 5 & 33.3 & \\
\hline \multirow[t]{2}{*}{ Cerebral hemisphere } & Right & 18 & 72.0 & 6 & 40.0 & 0.045 \\
\hline & Left & 7 & 28.0 & 9 & 60.0 & \\
\hline \multirow[t]{2}{*}{ Neurological degree } & $\leq 6($ mild $)$ & 13 & 52.0 & 7 & 46.7 & 0.744 \\
\hline & $>6($ severe $)$ & 12 & 48.0 & 8 & 53.3 & \\
\hline
\end{tabular}

The logistic regression models for insomnia complaints in the patients were constructed with variables that showed significant association, such as: sex, cerebral hemisphere affected, subjective sleep quality, latency, difficulty in falling asleep, and fragmented sleep. Of the five models built, the last best identified the variables related to insomnia complaint. The lower and upper limits of the confidence interval for the Odds Ratio (OR) indicated that the female sex and fragmented sleep can be considered risk factors for insomnia complaint in the sample studied (Table IV).

\section{DISCUSSION}

The results obtained for the PSQI score suggest that the patients, on average, experience poor sleep quality and had a higher latency, duration, and daytime dysfunction compared with control subjects. These data corroborate the results of an earlier study conducted by Campos et al. (2005) on poor sleep quality and the longer sleep duration of patients in the late stage of stroke recovery. This finding suggests that longer sleep duration is likely due to compensation for the poor sleep quality that these patients experience, indicating the possibility of behavioral modification after the cerebral lesion. In a study on drowsiness with elderly adults, Chasens et al. (2007) confirmed a relationship between drowsiness and sleep quality, given that individuals with daytime drowsiness reported worse sleep quality. Accordingly, sleep quality assessment has even greater clinical relevance in terms of its early identification in patients with a neurological lesion, such as those with stroke.

The results obtained for the frequency of sleep disorder complaints showed a significant difference between patients and controls with respect to insomnia complaint. Bassetti (2005) found that between $20 \%$ and $40 \%$ of patients experienced sleep-wake disorders. The most frequently observed sleep disorder complaints were: insomnia, excessive daytime drowsiness/ fatigue, and hypersomnia (increased need of sleep). This author suggests that the cerebral lesion itself, often at the thalamic or brain stem level, may be a cause for persistent sleep-wake 
TABLE IV

Logistic regression models (Odds Ratio, upper and lower limits of the $\mathbf{9 5 \%}$ confidence interval and p-value) considering sex, cerebral hemisphere affected, subjective sleep quality, latency, difficulty in falling asleep and fragmented sleep as independent variables sand insomnia complaint as the dependent variable.

\begin{tabular}{lcccc}
\hline VARIABLES & ODDS RATIO & LOWER & UPPER & $\boldsymbol{p}$ \\
\hline Model 1 & & & & \\
Sex & 22.401 & 1.253 & 400.501 & 0.035 \\
Cerebral hemisphere affected & 3.208 & 0.380 & 27.108 & 0.284 \\
Subjective quality & 11.353 & 0.728 & 176.993 & 0.083 \\
Latency & 0.800 & 0.081 & 7.928 & 0.849 \\
Difficulty in falling asleep & 3.835 & 0.458 & 32.119 & 0.215 \\
Fragmented sleep & 22.789 & 1.399 & 371.300 & $\mathbf{0 . 0 2 8}$ \\
Model 2 & & & & \\
Sex & 8.567 & 0.745 & 98.483 & 0.085 \\
Cerebral hemisphere affected & 2.338 & 0.334 & 16.371 & 0.392 \\
Lantency & 1.567 & 0.195 & 12.587 & 0.672 \\
Difficulty in falling asleep & 3.028 & 0.454 & 20.194 & 0.252 \\
Fragmented sleep & 20.776 & 1.729 & 246.725 & $\mathbf{0 . 0 1 7}$ \\
Model 3 & & & & \\
Sex & 9.991 & 0.967 & 103.213 & 0.053 \\
Cerebral hemisphere affected & 2.158 & 0.327 & 14.264 & 0.425 \\
Difficulty in falling asleep & 3.392 & 0.547 & 21.037 & 0.190 \\
Fragmented sleep & 25.862 & 2.467 & 271.126 & $\mathbf{0 . 0 0 7}$ \\
Model 4 & & & & \\
Sex & 11.578 & 1.171 & 114.518 & $\mathbf{0 . 0 3 6}$ \\
Difficulty in falling asleep & 3.683 & 0.609 & 22.290 & 0.156 \\
Fragmented sleep & 29.733 & 2.763 & 319.919 & $\mathbf{0 . 0 0 5}$ \\
Model 5 & & & & \\
Sex & & 1.167 & 105.559 & $\mathbf{0 . 0 3 6}$ \\
Fragmented sleep & 32.040 & 317.261 & $\mathbf{0 . 0 0 3}$ \\
\hline & & & \\
\hline
\end{tabular}

disorders. An analysis of only sleep complaint in the present study shows a relevant frequency of $37.5 \%$ in the patients who suffered a stroke, but in only $6.7 \%$ of the controls. These values corroborate the data of an earlier study by Leppavuori et al. (2002) about the frequency of insomnia in patients with stroke, but with a higher relevant frequency $(56.7 \%)$, possibly due to the more advanced age range (55 to 85 years) and to the shorter lesion time (3 to 4 months).

Complaints of obstructive sleep apnea, restless legs, nightmares, teeth grinding, sleep talking and snoring studied did not differ statistically in frequency between the patients and controls, likely because it is seldom self-reported, and for this reason both groups rarely mentioned these complaints. According to Masel et al. (2001), the prevalence of sleep apnea syndrome, periodic limb movement disorder and hypersomnia in patients with cerebral lesion, may cause excessive daytime drowsiness. This finding suggests that polysomnographic assessment should be considered as part of the investigation of patients with cerebral lesion to complement the subjective evaluation. 
A relationship between sleep quality and sex was reported by Wells et al. (2004) in which women experienced worse sleep quality than did men. However, these results were not found in the present study, likely owing to a number of differences in the present investigation in terms of age range and pathology. With respect to the clinical variables, no significant difference was found between the patients with poor and good sleep quality as to lesion time, cerebral hemisphere affected and neurological degree.

Among the predictive factors of sleep quality assessed, insomnia complaint and latency were the most influential. In this case, the lack of insomnia complaint and decreased latency may be considered strong protective factors of sleep quality. Thus, the clinical evaluation will be important to investigate complaints of insomnia patients and those being confirmed should assess sleep latency through proper screening and confirm whether or not a diagnosis of insomnia.

Our study also proposed to investigate the predictive factors of sleep complaint. The results of the associations between sleep complaint in the patients with stroke and the demographic and clinical variables and PSQI components, showed significant differences. These findings indicate that the presence of insomnia complaint in patients with stroke was associated to the female sex, the impaired right cerebral hemisphere, presence of fragmented sleep complaints, difficulty in falling asleep, alterations in sleep latency (greater sleep latency) and subjective sleep quality (worse subjective sleep quality).

The study conducted by Leppavuori et al. (2002) analysed insomnia in patients with stroke and observed that those with insomnia were more frequently women and older than patients without insomnia, suggesting a relationship between insomnia complaint in patients with stroke and the female sex as well as advanced age. This sex-related finding confirms the association between insomnia complaint in patients with stroke and the female sex observed in the present study. However, the age association observed by the aforementioned authors was not found in the present study, likely because the sample study of Leppavuori et al. (2002) was composed of older individuals than the patients of our study. The association between insomnia complaint and impaired right cerebral hemisphere does not corroborate the results of Leppavuori et al. (2002), in which patients with stroke and insomnia complaint suffered more frequently from left hemispheric lesion. With respect to the association between insomnia complaint and the other sleep disturbances, a relationship was found only between insomnia and fragmented sleep complaint and difficulty in falling asleep. Despite the associations found, multivariate analysis showed that the female sex and fragmented sleep complaint were risk factors for insomnia complaint in patients with stroke.

The study has a number of limitations that must be considered. The sample of patients could have shown greater variability in neurological degree, thereby enabling a more thorough analysis of the association between sleep quality and sleep disorder complaints, according to the level of clinical impairment. Another limitation was the impossibility of correlating the cerebral areas affected with the sleep disorders of the patients, because the neuroimaging examinations were performed at different hospitals, precluding standardization of the medical reports. Despite these limitations, the study identified that insomnia complaint and decreased latency were the most important predictive factors of poor sleep quality in the patients. In addition, the female sex and fragmented sleep complaint can be considered the main predictive factors for insomnia complaint in the sample studied. Future studies may be conducted to assess if the implementation of sleep disorder treatment would effectively improve the rehabilitation potential of patients with stroke. 


\section{ACKNOWLEDGMENTS}

This research was supported by Programa de Apoio à Pós-Graduação (PROAP) / Coordenação de Aperfeiçoamento de Pessoal de Nível Superior (CAPES).

\section{RESUMO}

As queixas sobre os problemas do sono não têm sido bem identificadas após um Acidente Vascular Encefálico (AVE). O objetivo deste estudo foi investigar os fatores preditivos da qualidade do sono e das queixas de insônia em pacientes com AVE. Participaram 70 indivíduos, 40 pacientes (57 \pm 7 anos) e 30 controles saudáveis (52 \pm 6 anos) que foram avaliados pelo Índice de Qualidade de Sono Pittsburgh (IQSP) e Questionário de Hábitos do Sono. Os dados foram analisados pelo teste $t$ de Student e regressão logística. Em média, os pacientes apresentaram má qualidade do sono (pacientes: 6,3 \pm 3,5; controles: $3,9 \pm 2,2, p=0,002$ ) e a queixa de insônia foi a mais prevalente (pacientes: $37,5 \%$; controles: $6,7 \%, p=0,007)$. A ausência de queixa de insônia $(\mathrm{OR}=$ $0,120$ IC $95 \%=0,017-0,873, p=0,036)$ e a diminuição da latência do sono (OR $=0,120$ IC $95 \%=0,017-0,873$, $\mathrm{p}=0,036)$ foram os fatores de proteção da qualidade do sono. Sexo feminino $(\mathrm{OR}=11,098$; IC $95 \%=1,167$ $105,559, \mathrm{p}=0,036)$ e sono fragmentado $(\mathrm{OR}=32,040$; IC $95 \%=3,236-317,261, p=0,003)$ foram os fatores de risco para a queixa de insônia. Nós sugerimos que as queixas de má qualidade do sono e da insônia sejam priorizadas durante o diagnóstico clínico dos distúrbios do sono no AVE.

Palavras-chave: insônia, distúrbios do sono, qualidade do sono, acidente vascular Encefálico.

\section{REFERENCES}

AASM - AMERICAN ACADEMy of SLeEP Medicine. 2001. International classification of sleep disorders, revised: diagnostic and coding manual. Chicago, $401 \mathrm{p}$.

BASSETTI C. 2005. Sleep and stroke. Semin Neurol 25: 19-32.

Buysse DJ, Reynolds CF, Monk TH, Berman SR AND KUPFER DJ. 1989. The Pittsburgh Sleep Quality Index: a new instrument for psychiatric practice and research. Psychiatry Res 28: 193-213.
CAMpos TF, DiÓGenes FP, FRANÇA FR, DANTAS RCS, ARAÚJO JF AND MENEZES AAL. 2005. The sleep-wake cycle in the late stage of cerebral vascular accident recovery. Biol Rhyt Res 36: 109-113.

Caneda M, Fernandes J, Almeida A and Mugnol F. 2006. Reliability of neurological assessment scales in patients with stroke. Arq de Neuropsiquiatr 64: 690-697.

CEOLIM MF. 1999. Padrões de atividade e de fragmentação do sono em pessoas idosas. Tese de Doutorado, Universidade de São Paulo.

ChARTIER-KASTLER E AND DAVIDSON K. 2007. Evaluation of quality of life and quality of sleep in clinical practice. Eur Urol Sup 6: 576-584.

Chasens ER, Sereika SM, Weaver TE and Umlauf MG. 2007. Daytime sleepiness, exercise, and physical function in older adults. J Sleep Res 16: 60-65.

Coca A, Messerli FH, Benetos A, Zhou Q, Champion A, Cooper-Dehoff RM And PePIne PCJ. 2008. Predicting stroke risk in hypertensive patients with coronary artery disease: a report from the INVEST. Stroke 39: 343-348.

Curcio G, Ferrara M AND GenNARo LD. 2006. Sleep loss, learning capacity and academic performance. Sleep Med Rev 10: 323-337.

Ferrea A, Ribób M, RodríGuez-LunAB D, RomeroA O, SAmpolc G, Molinab CA AND Álvarez-SABInB J. 2010. Los ictus y su relación con el sueño y los trastornos del sueño. Neurol 10: 1-16.

GALLASCH J AND GRADISAR M. 2007. Relationships between sleep knowledge sleep practice and sleep quality. Sleep Bio Rhyth 5: 63-73.

Horne JA AND Östberg O. 1976. A self-assessment questionnaire to determine morningness-eveningness in human circadian rhythms. Int J Chronobiol 4: 97-110.

Koch S, Zuniga S, Rabinstein AA, Romano JG, Nolan B, Chirinos J AND FortezA A. 2007. Signs and symptoms of sleep apnea and acute stroke severity: is sleep apnea neuroprotective? J Stroke Cerebrovasc Dis 16: 114-118.

LeppaVuori A, POHJASVAARA T, VATAJA R, KASTE M AND ERKINJUNTTI T. 2002. Insomnia in ischemic stroke patients. J Stroke Cerebrovasc Dis 14: 90-97.

Lotufo PA. 2005. Stroke in Brazil: a neglected disease. São Paulo Med J 123: 3-4.

Masel BE, Scheibel RS, Kimbark T AND KunA ST. 2001. Excessive daytime sleepiness in adults with brain injuries. Arch Phys Med Rehabil 82: 1526-1532.

PARMELEE PA, ThURAS PD, KATZ IR AND LAWTON MP. 1995. Validation of the Cumulative Illness Rating Scale in a geriatric residential population. J Am Geriatr Soc 43: 130-137.

Pontes-Neto OM, Silva GS, Feitosa MR, De Figueiredo NL, FIOROT JA JR, RochA TN, MASSARO AR AND LEITE JP. 2008. Stroke awareness in Brazil: alarming results in a community-based study. Stroke 39: 292-296.

SriJtThesh PR, ShuKla G, SrivastaV A, Goyal V, Singh S AND BEHARI M.2011. Validity of the Berlin Questionnaire in identifying obstructive sleep apnea syndrome when administered to the informants of stroke patients. J Clin Neurosci 18: 340-343. 
VINHA D, CAVAlCANTE J AND ANDRADE MMM. 2002. Sleepwake patterns of workers and non-workers students. Biol Rhythm Res 33: 417-426.

Wells RD, DAY RC, CARNEY RM, FREEDland KE AND DUNTLEY SP. 2004. Depression predicts self-reported sleep quality in patients with obstructive sleep apnea. Psychosom Med 66: 692-697.
Wright KP JR, HULL JT, HUGHES RJ, RONDA JM AND CZEISLER CA. 2006. Sleep and wakefulness out of phase with internal biological time impairs learning in humans. J Cogn Neurosci 18: 508-521. 